J. Lake Sci. (湖泊科学), 2012, 24(2):232-237

http: //www. jlakes.org. E-mail : jlakes@niglas.ac.cn

(C) 2012 by Journal of Lake Sciences

\title{
三峡水库蓄水后对支流大宁河富营养化特征及水动力的影响”
}

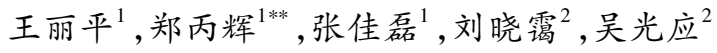 \\ (1: 中国环境科学研究院河流与海岸带环境研究室,北京 100012) \\ (2: 重庆市巫山县环境监测站,巫山 404700)
}

\begin{abstract}
摘 要: 三峡水库蓄水后支流大宁河水华频发,为了揭示水库蓄水以来,大宁河富营养化变化趋势以及水华暴发期间水 动力等环境因子的影响特征, 自 2005 年长期跟踪监测大宁河的水质状况, 并于 2010 年针对东坪坝库湾 2 次典型水华事 件,初步探讨了水华暴发期间的主要影响因素. 结果表明:2005 年以来,大宁河水体处于中度营养状态,水质尚好,但低估 了水华敏感期的富营养化状况. 东坪坝 3 月水华暴发期间, 叶绿素 a 浓度与流速呈显著负相关,与 $\mathrm{pH} 、 \mathrm{DO}$ 也呈显著相关, 表明在此次水华期间, 流速对藻细胞的增殖或聚集产生直接或间接的影响, $\mathrm{pH}$ 和 DO 是引起水华暴发的主要水质因子;5 月水华暴发期间, 叶绿素 a 浓度与流速呈显著负相关, 与流量呈显著正相关, 同时与 $\mathrm{pH}$ 、透明度 $(\mathrm{SD})$ 呈显著相关, 表明在 这次水华期间, 流速和流量都对藻细胞增殖或聚集产生直接或间接的影响, $\mathrm{pH}$ 和 $\mathrm{SD}$ 成为水质敏感因子. 3 月和 5 月水华 暴发时间分别处于水库高水位运行期和泄水期,这可能是导致水华影响因子不同的主要原因,但具体机理还有待于进一 步研究. 本文结果表明在三峡水库调度运行的不同阶段支流库湾水华暴发的机制不同,需要针对不同时段支流库湾水环 境特征分别加以调查研究.
\end{abstract}

关键词: 三峡水库;大宁河;富营养化;水动力条件

\section{Effects on euthrophication and hydrodynamics of Daning River after impoundment of Three Gorges Reservoir}

\author{
WANG Liping $^{1}$, ZHENG Binghui ${ }^{1}$, ZHANG Jialei ${ }^{1}$, LIU Xiaoai ${ }^{2} \&$ WU Guangying ${ }^{2}$ \\ (1: River and Coastal Environment Research Center, Chinese Research Academy of Environmental Sciences, Beijing 100012, \\ P. R. China) \\ (2: Environmental Monitoring Station of Wushan in Chongqing, Wushan 404700, P. R. China)
}

\begin{abstract}
Algal blooms have occurred frequently in the backwater region of the Daning River branch since the impoundment of the Three Gorges Reservoir( TGR). In order to assess the water quality status and the driving factors on algal bloom outbreak, the water quality has been monitored since 2005, and 2 typical algal blooms, occurred in Dongpingba in March and May 2010, were investigated. Results showed that Daning River was mesotrophic and water quality was good, nevertheless the trophic grade was underestimated for the period of algal bloom outbreak. For algal bloom in March, there was a significant negative correlation between Chl. a concentration and velocity, while obvious relationships in Chl. a and $\mathrm{pH}$ or DO, indicating that velocity was an important factor for this bloom outbreak and $\mathrm{pH}$, DO were sensitive factors caused by bloom. For algal bloom in May, there was a significant negative correlation between Chl. a concentration and velocity, while a significant positive correlation between Chl. a and flow quantity, and also obvious relationship in Chl. a and $\mathrm{pH}$, SD. It indicated that velocity and flow quantity were important factors for algal bloom outbreak in May, and pH, SD became the sensitive indices. According to the operational schedules of TGR, March and May belong to the period with high water level and discharge, respectively. Schedule times with different hydrodynamics may be responsible for the difference of effect factors on algal bloom, but the mechanism need to be further studied. Results suggested that the algal bloom mechanism in the different operational schedules of TGR is different from each other significantly. Therefore, the study on algal bloom in backwater region of Daning River need to be performed according to the operational schedule of TGR.
\end{abstract}

* 国家水体污染控制与治理科技重大专项项目 (2009ZX07528-003) 资助. 2011-10-01 收稿; 2011- 11-28 收修改 稿.王丽平,女,1974 年生,副研究员;E-mail: wanglp@ craes. org. cn.

** 通信作者;E-mail: zhengbh@ craes. org. cn. 
Keywords: Three Gorges Reservoir; Daning River; eutrophication; hydrodynamic condition

富营养化是三峡水库当前亟待解决的问题之一 ${ }^{[1-2]}$. 研究表明自三峡水库蓄水和功能调度以来, 水库及 其支流水位提高、水流速度减慢, 支流库湾水华频繁发生 ${ }^{[3]}$, 水动力条件的改变是支流库湾水华频发的主要 原因 ${ }^{[4-7]}$. 在对其他水体富营养化的相关研究中, 结果都表明水华暴发与水动力条件呈显著相关 ${ }^{[8-11]}$. 流速能 够改变水体的物理过程和营养盐浓度, 同时也对藻类增殖、群落组成及其空间分布产生直接影响 ${ }^{[8,12]}$.

大宁河流域位于三峡库区的腹心地带, 蓄水后河水流速大大减缓, 河面增宽, 其回水段水域成为水 库发生富营养化的敏感区域, 多次暴发藻类水华 ${ }^{[13-15]}$. 本文根据三峡水库蓄水以来连续 $6 \mathrm{a}(2005-$ 2010 年) 的监测数据综合分析了大宁河的富营养化变化特征, 并选择大宁河典型库湾东坪坝作为代 表, 针对 2010 年的 2 次典型水华事件, 综合分析流速、流量以及水质因子与水华暴发的相关关系, 初 步探讨大宁河库湾水华暴发的主要水动力影响因素和水质敏感因子, 以期为大宁河水华暴发机理研 究提供基础信息.

\section{1 材料和方法}

大宁河 $\left(31^{\circ} 02^{\prime} \sim 31^{\circ} 20^{\prime} \mathrm{N}, 109^{\circ} 30^{\prime} \sim 110^{\circ} 01^{\prime} \mathrm{E}\right)$ 距离三 峡大坝约 $123 \mathrm{~km}$, 其回水水域主要位于重庆市巫山县境内. 三峡水库支流大宁河水质的采样站位见图 1, 采样断面包括 大昌、双龙、东坪坝、白水河和菜子坝. 采样时间为 20052010 年 1-12 月逐月监测, 样品为表层水样. 检测指标包括 透明度 $(\mathrm{SD})$ 、水温 $(T) 、 \mathrm{pH}$ 、溶解氧 $(\mathrm{DO})$ 、高锰酸盐指数 $\left(\mathrm{COD}_{\mathrm{Mn}}\right)$ 、总氮 $(\mathrm{TN})$ 、总磷 $(\mathrm{TP})$ 和叶绿素 $\mathrm{a}(\mathrm{Chl} . \mathrm{a}) . \mathrm{SD}$ 采 用塞式盘法测定, $T 、 \mathrm{pH}$ 和 DO 采用便携式水质分析仪测定, 其它指标按照《水和废水监测分析方法》测定 ${ }^{[16]}$. 选用综合 营养状态指数 $(T L I)$ 评价大宁河水体的富营养化状态 ${ }^{[17-18]}$, $T L I<30$, 为贫营养; $30 \leqslant T L I \leqslant 50$, 为中营养; $T L I>50$, 为富

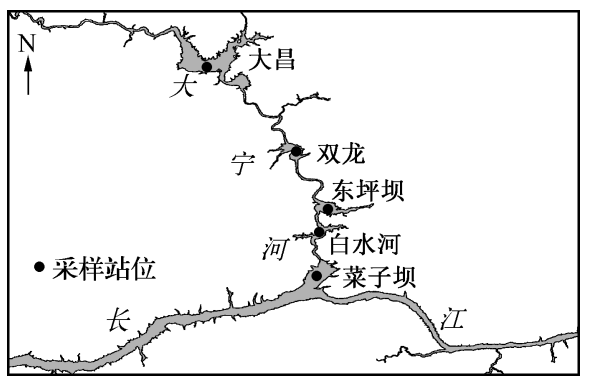

图 1 大宁河采样站位

Fig. 1 Sampling stations in Daning River 营养.

东坪坝是大宁河中下游一个重要的回水区, 几乎每年春、夏季都有水华暴发 ${ }^{[15,19]}, 2010$ 年 3 月 $12-18$ 日和 5 月 18-20 日东坪坝水体明显变色, 且藻细胞密度高于 $10^{6} \mathrm{cells} / \mathrm{L}$, 远远超过富营养化水平 ${ }^{[20]}$, 出现水 华暴发, 在此期间分别利用美国 SonTek 多普勒测流仪 (SonTek/YSI-ADP) 对东坪坝 ( $31^{\circ} 08^{\prime} 40^{\prime \prime} \mathrm{N}$, $\left.109^{\circ} 32^{\prime} 18^{\prime \prime} \mathrm{E}\right)$ 断面进行流速 $(V)$ 、流量 $(Q)$ 测定, 并对该断面水体 $T 、 \mathrm{pH} 、 \mathrm{DO} 、 \mathrm{SD} 、 \mathrm{Chl}$. a 浓度进行同步监测, 监测频率为每天 2 次. 水质因子分别在东坪坝断面左、中、右表层 $0.5 \mathrm{~m}$ 处测定; 多普勒测流仪测量牵引船从 东坪坝断面一侧行驶至另一侧过程中每 $20 \mathrm{~s}$ 输出 1 次数据. 最后对各监测数据进行标准化后, 采用 SPSS 13.0 对 $\lg$ (Chl. a) 和各水环境参数的相关关系进行分析.

\section{2 结果与分析}

三峡水库蓄水后, 2005-2010 年大宁河水体 TP、TN、SD 和 Chl. a 的逐月动态变化见图 2, 根据湖库水 质评价标准 ${ }^{[21]}$, TP 基本处于贫一中营养状态, 而 $\mathrm{TN}$ 处于富营养状态, 透明度在 $0.5 \sim 4.5 \mathrm{~m}$ 之间波动. 大 宁河水体 $T L I$ 在 $23.20 \sim 48.86$ 之间, 除个别月份水体为贫营养外, 绝大部分时间水体基本处于中营养状 态(图 3).

2010 年 3 月、 5 月巡测期间发现大宁河的几个典型库湾水体异样, 经过检测藻细胞密度明显高于富营养 化水平 ${ }^{[20]}$, 出现水华,其暴发时间及主要特征见表 1 . 浮游藻类鉴定表明这几次水华优势种各不相同, 且 3 月在大宁河 4 个库湾同时出现甲藻水华, 而 5 月在 2 个库湾同时出现团藻水华. 另外在同一库湾 (如东坪 坝、白水河)不同时间出现不同类型的水华. 

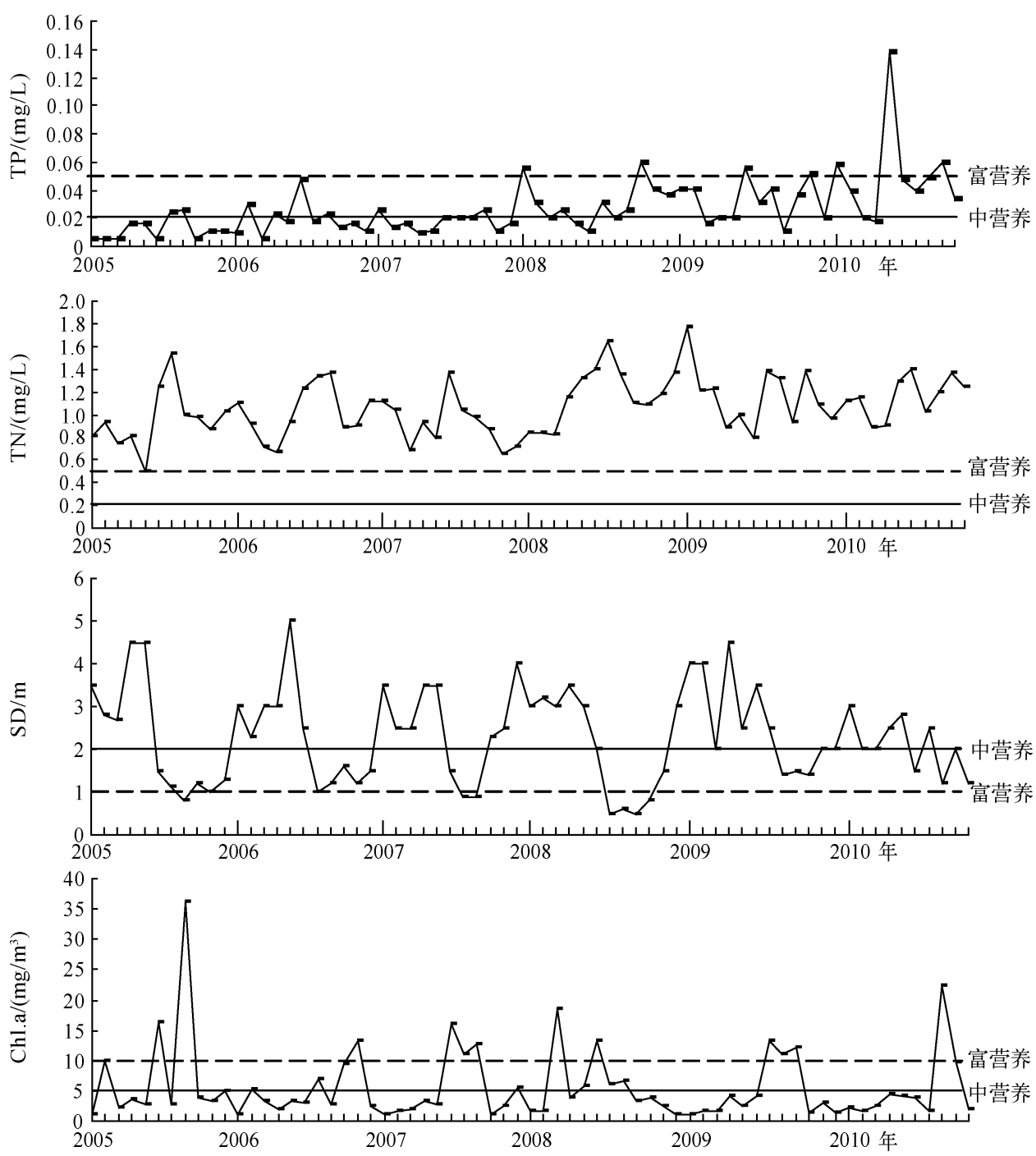

图 2 2005-2010 年大宁河 TP、TN、SD 和 Chl. a 的变化趋势

Fig. 2 TP, TN, SD and Chl. a of Daning River from 2005 to 2010

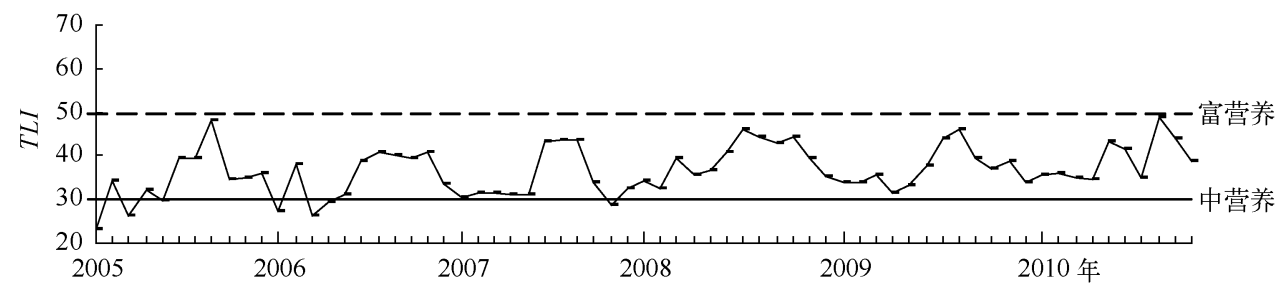

图 3 2005-2010 年大宁河综合富营养化状态指数变化趋势

Fig. 3 The Trophic Level Index of Daning River from 2005 to 2010 
表 1 大宁河 2010 年几次典型水华事件及其主要特征

Tab. 1 Characters of the main algal blooms in Daning River in 2010

\begin{tabular}{llcl}
\hline 时间 & 地点 & 藻密度 $/\left(\times 10^{6}\right.$ cells/L) & 优势种 \\
\hline $2010-03-12 \sim 18$ & 菜子坝、白水河、东坪坝、双龙 & $3.87 \sim 5.04$ & 拟多甲藻 (Peridiniopsis sp. ) \\
$2010-05-18 \sim 20$ & 东坪坝、白水河 & $1.66 \sim 5.39$ & 团藻 (Volvox sp. ) \\
$2010-06-18$ & 白水河 & 20.77 & 微囊藻 (Microcystis sp. ) \\
$2010-07-12$ & 白水河 & 49.49 & 颤藻 (Oscillatoria sp. ) \\
\hline
\end{tabular}

3.5 月东坪坝水华暴发期间 Chl. a 浓度和水环境参数监测结果见表 2.2010 年 3 月东坪坝库湾水华暴发 期间, Chl. a 浓度与 $V$ 呈显著负相关, 与 $\mathrm{pH} 、 \mathrm{DO}$ 也呈显著相关; 水体 $\mathrm{pH}$ 与 DO、 $V$ 显著相关, DO 与 $V$ 显著相 关. 5 月东坪坝库湾水华暴发期间, Chl. a 浓度与 $V$ 呈显著负相关, 与 $Q$ 呈显著正相关, 同时与 $\mathrm{pH} 、 \mathrm{SD}$ 也呈显 著相关;水体 $\mathrm{pH}$ 与 $V 、 Q$ 显著相关; $V$ 与 $Q$ 显著相关 (表 3 ).

表 22010 年 3 月和 5 月水华期东坪坝的水环境特征

Tab. 2 Water environment character during algal blooms outbreak of Dongpingba region in March and May, 2010

\begin{tabular}{cccccccc}
\hline 时间 & $\mathrm{Chl.a} /\left(\mathrm{mg} / \mathrm{m}^{3}\right)$ & $T /{ }^{\circ} \mathrm{C}$ & $\mathrm{pH}$ & $\mathrm{DO} /(\mathrm{mg} / \mathrm{L})$ & $\mathrm{SD} / \mathrm{m}$ & $V /(\mathrm{m} / \mathrm{s})$ & $Q /\left(\mathrm{m}^{3} / \mathrm{s}\right)$ \\
\hline 3 月 & $22.3 \sim 46.5$ & $11.5 \sim 12.6$ & $8.1 \sim 9.1$ & $8.4 \sim 9.5$ & $0.5 \sim 1.5$ & $0.02 \sim 0.75$ & $-214 \sim-353$ \\
5 月 & $16.8 \sim 48.9$ & $17.9 \sim 19.8$ & $8.3 \sim 9.2$ & $8.8 \sim 9.6$ & $0.6 \sim 1.6$ & $0.08 \sim 0.74$ & $-33 \sim-198$ \\
\hline
\end{tabular}

表 3 东坪坝 2010 年 3 月 (左下三角) 和 5 月 (右上三角) 水华期叶绿素 a 和各环境因子的相关关系

Tab. 3 The relationships between Chl. a concentration and environmental factors during algal blooms outbreak of Dongpingba region in March(left-bottom triangle) and May (right-up triangle) , 2010

\begin{tabular}{ccrcrrrr}
\hline 3月/5 月 & $\lg$ (Chl. a $)$ & \multicolumn{1}{c}{$T$} & $\mathrm{pH}$ & $\mathrm{DO}$ & $\mathrm{SD}$ & \multicolumn{1}{c}{$Q$} \\
\hline $\lg ($ Chl. a $)$ & $\mathbf{1 . 0 0 0}$ & 0.549 & $0.831^{* *}$ & -0.555 & $-0.751^{*}$ & $-0.769^{*}$ & $0.668^{*}$ \\
$T$ & -0.365 & $\mathbf{1 . 0 0 0}$ & 0.465 & -0.548 & -0.465 & -0.514 & 0.503 \\
$\mathrm{pH}$ & $0.852^{* *}$ & -0.169 & $\mathbf{1 . 0 0 0}$ & -0.461 & -0.565 & $-0.804^{* *}$ & $0.729^{*}$ \\
$\mathrm{DO}$ & $-0.875^{* *}$ & 0.384 & $-0.887^{* *}$ & $\mathbf{1 . 0 0 0}$ & 0.487 & 0.270 & -0.482 \\
$\mathrm{SD}$ & -0.580 & -0.011 & -0.320 & 0.490 & $\mathbf{1 . 0 0 0}$ & 0.210 & -0.228 \\
$V$ & $-0.843^{*}$ & 0.491 & $-0.683^{*}$ & $0.741^{*}$ & 0.386 & $\mathbf{1 . 0 0 0}$ & $-0.791^{* *}$ \\
$Q$ & -0.531 & -0.054 & -0.551 & 0.463 & 0.144 & 0.105 & $\mathbf{1 . 0 0 0}$ \\
\hline
\end{tabular}

*代表 $P<0.05 ; * *$ 代表 $P<0.01$.

\section{3 讨论}

根据每月 1 次常规监测数据进行的富营养化评价结果, 大宁河基本处于中营养状态 (图 2), 水质尚好. 但这些监测数据都是在每月固定时间进行采样, 采样期间几乎不能获得水华暴发过程中的水环境资料, 只 能显示大宁河富营养化状态的长期变化趋势, 对某些特殊时间段 (如水华暴发期间) 的富营养化状态会有所 低估. 因此 2010 年我们在进行常规监测的同时, 加密巡测, 发现水华立即对暴发期间的各项相关指标加以 监测, 以期获得大宁河库湾水华暴发过程中的主要敏感因子, 为水华预测预警提供基础参数. 2010 年在东坪 坝监测到 2 次典型水华暴发 (表 1), 相关分析表明 3 月水华期间, $V 、 \mathrm{pH}$ 和 DO 都与 Chl. a 浓度呈显著相关;5 月水华期间, $V 、 Q$ 和 $\mathrm{pH} 、 \mathrm{SD}$ 都与 Chl. a 浓度呈显著相关. 其中 $\mathrm{pH} 、 \mathrm{DO}$ 和 $\mathrm{SD}$ 是水华暴发的结果而非原 因 ${ }^{[22]} .2010$ 年三峡水库已经正常调度运行, 3 月和 5 月分别处于调度运行的两个不同阶段, 3 月为高水位运 行期, 为迎接汛期的到来, 5 月水库开始开闸放水, 因此 3 月和 5 月大宁河库湾的水动力条件可能不尽相同, 对水华暴发的影响机制也会有所不同,其确切机制还有待于进一步调查和研究.

水华生消是适宜的环境条件、充足的营养盐和缓慢的水动力条件共同作用的结果. 三峡水库蓄水前后 
大宁河所在区域的环境条件 (如气温、光照等)变化不大, 蓄水后其回水区暴发水华, 因此除了水体水质达富 营养化条件外, 另一主要因素是回水区水动力条件的改变. 根据 2005-2010 年的长期跟踪监测数据, 20052008 年 TP 在部分季节低于国际公认发生富营养化的浓度水平 $(0.02 \mathrm{mg} / \mathrm{L}), 2009-2010$ 年 TP 常年超过 $0.02 \mathrm{mg} / \mathrm{L}$; 而 TN 常年都超过国际公认的发生富营养化的浓度水平 $(0.2 \mathrm{mg} / \mathrm{L})^{[17]}$, 因此 2010 年 3 月和 5 月 大宁河具备水华暴发的营养盐条件,所以水动力条件应该是导致大宁河库湾水华暴发的重要因素. 本研究 的相关分析发现: Chl. a 浓度与 $V$ 或 $Q$ 呈显著相关, 也从一定程度上证明了这一点. 另外有研究表明水体的 各种运动形式造成了生物体和生源要素在不同空间尺度的分布,使水体环境发生改变并影响着库区和河流 水生生物的组成、数量以及分布 ${ }^{[23-24]}$. 叶麟等 ${ }^{[25]}$ 研究发现, 香溪河库湾春季水华期间硝酸盐、磷酸盐存在明 显的时空分布规律, $\mathrm{NO}_{3}^{-}-\mathrm{N}$ 浓度从上游至河口逐渐降低, $\mathrm{PO}_{4}^{3-}-\mathrm{P}$ 则正好相反. 如此完全相反的空间分布规 律, 必然会使得 $\mathrm{NO}_{3}^{-}-\mathrm{N} / \mathrm{PO}_{4}^{3-}-\mathrm{P}$ 的比值在香溪河库湾中出现很大的变化幅度, 从而对浮游植物的生长及其 种群组成产生一定的影响 ${ }^{[26]}$. 大宁河水流的总体方向是由上游流向下游, 而三峡蓄水期间水流水动力环境 有很大改变, 由于水库水位的不断升高, 长江干流密度较大的水流更容易进人支流库湾, 与库湾水体进行掺 混和交换,必然会改变营养盐浓度和结构分布特征. 本研究发现大宁河几次水华的优势种并不单一(表 1$)$, 且具有不同河段同时暴发不同类型水华,相同河段不同时间出现同一类型水华的现象 ${ }^{[27]}$,这种特征可能与 在三峡水库不同运行阶段对大宁河水动力条件产生不同影响相关.

先前关于三峡水库水动力条件对藻类生长的影响研究中都指出, 流速在支流水华暴发过程中起着重要 的作用. 黄程等采用圣维南 (Saint-Venanf) 方程组模拟三峡库区大宁河库湾的水动力条件, 并利用大宁河库 湾现场监测结果对流速与藻类生长关系进行曲线拟合, 获得的流速与藻类生长关系模型为 $y=34.042-$ $293.725 u+821.265 u^{2}-603.45 u^{3}$, 并指出在气候条件和营养盐条件适宜的情况下, 流速与藻类浓度呈显著 负相关, 流速成为主要的限制因子 ${ }^{[28]}$. 龙天渝等针对三峡库区低流速河段浮游藻类的生长特点, 结合实验室 模拟研究探讨了湖泊型和河流型流速状态下蓝、绿、硅藻在真光层沿垂直方向分布规律的影响,结果表明湖 泊型流速 $(<0.05 \mathrm{~m} / \mathrm{s})$ 下, 蓝、绿、硅藻细胞的峰值分别出现在距水面 $0 \sim 60 、 40 \sim 80 、 120 \sim 140 \mathrm{~cm}$ 水深范围 内; 河流型流速 $(0.1 \sim 0.5 \mathrm{~m} / \mathrm{s})$ 下, 硅藻细胞密度的峰值明显上升至 $40 \sim 80 \mathrm{~cm}$ 水深处, 随着流速的加快, 硅 藻在各个水深均呈现上浮趋势, 而蓝藻处于下浮趋势 ${ }^{[29]}$. 因此, 流速对藻细胞的增殖、聚集和分布都有一定 的影响. 本文针对 2010 年 3 月和 5 月大宁河东坪坝暴发的 2 次水华,运用现场监测资料初步探讨了水体流 速、流量对水华暴发的影响以及相应的水质敏感因子, 结果表明在三峡水库不同运行阶段支流库湾的水动 力条件不同,对水华暴发的影响机制也存在明显差异,水华暴发对水质的影响结果也不尽相同. 所以在对三 峡水库支流库湾水华暴发机理的研究中,需要针对不同运行阶段分别加以调查研究.

\section{4 参考文献}

[ 1 ] Shen ZL, Qun L. Nutrients in the Changjiang River. Environ Monit Assess, 2009, 153: $27-44$.

[ 2 ] Dai HC, Zheng TG, Liu DF. Effects of reservoir impounding on key ecological factors in the Three Gorges region. Procedia Environ Sci, 2010, 2: 15-24.

[ 3 ] Zeng H, Song LR, Yu ZG et al. Distribution of phytoplankton in the Three Gorge Reservoir during rainy and dry seasons. Sci Total Environ, 2006, 367: 999-1009.

[ 4 ] Chen YC, Fu J, Liu ZW et al. Evaluation of water quality near the dam before and after the storage of Three Gorges Reservoir. J Hydroelec Eng, 2007, 26(4) : 51-54.

[ 5 ] Dai HC, Dai DG. Changes and countermeasures of reservoir water quality after storage of Three Gorges Reservoir. Preceedings of 16th IAHR-APD Congress and 3rd Symposium of IAHR-ISHS, 2008: 2260-2266.

[6] 周广杰, 况琪军, 胡征宇等. 三峡库区四条支流藻类多样性评价及 ‘水华’ 防治. 中国环境科学, 2006, 26(3) : $337-341$.

[ 7 ] 杨 敏, 毕永红, 胡建林等. 三峡水库香溪河库湾春季水华期间浮游植物昼夜垂直分布与迁移. 湖泊科学, 2010, $23(3): 375-382$.

[ 8 ] Arhonditsis GB, Stow CA, Paerl HW et al. Delineation of the role of nutrient dynamics and hydrologic forcing on phytoplankton patterns along a freshwater-marine continuum. Ecol Model, 2007,208 : 230-246. 
[ 9 ] Gameiro C, Cartaxana P, Brotas V. Environmental divers of phytoplankton distribution and composition in Tagus Estuary, Portugal. Estuarine Coastal and Shelf Science, 2007, 75 : 21-34.

[10 ] Becker V, Huszer VLM, Crossetti LO. Responses of phytoplankton functional groups to the mixing regime in a deep subtropical reservoir. Hydrobiologia, 2009, 628: 137-151.

[11] Xu J, Yin K, Liu H et al. A comparison of eutrophication impacts in two harbours in Hong Kong with different hydrodynamics. J Mar Sys, 2010, 83: 276-286.

[12] Paerl HW, Valdes LM, Adolf J et al. Anthropogenic and climatic influences on the eutrophication of large estuarine ecosystems. Limnol Oceanogr, 2006, 51: 448-462.

[13] 郑丙辉, 曹承进, 秦延文等. 三峡水库主要人库河流氮营养盐特征及其来源分析. 环境科学, 2008, 29(1)：1-6.

[14] 曹承进. 三峡水库富营养化分析及水华预警研究 [学位论文]. 上海: 华东师范大学, 2009.

[15] Zhang JL, Zheng BH, Liu LS et al. Seasonal variation of phytoplankton in the Daning River and its relationships with environmental factors after impounding of the Three Gorges Reservoir: a four-year study. Procedia Environ Sci, 2010,2 : 1479-1490.

[16] 国家环境保护总局《水和废水监测分析方法》编委会. 水和废水监测分析方法:第 4 版. 北京: 中国环境科学出版 社, 2002.

[17] 金相灿, 刘淑坤, 张宗涉. 中国湖泊环境. 北京: 海洋出版社, 1995 .

[18］中国环境监测总站. 湖泊(水库)富营养化评价方法及分级技术规定. 2001 .

[19] 曹承进, 郑丙辉, 张佳否等. 三峡水库支流大宁河冬、春季水华调查研究. 环境科学, 2009, 30(12): 3471-3480.

[20］顾丁锡. 湖泊富营养化评价方法. 环境污染与防治, 1982, 3: 14-17.

[21] 钟成华. 三峡库区水体富营养化研究 [学位论文]. 成都: 四川大学, 2004.

[22] Wang XL, Lu YL, He GZ et al. Exploration of relationships between phytoplankton biomass and related environmental variables using multivariate statistic analysis in a eutrophic shallow lake: A 5-year study. J Environ Sci, 2007, 19: $920-927$.

[23] Schemel LE, Sommer TR, Müller-Solger AB et al. Hydrologic variability, water chemistry, and phytoplankton biomass in a large floodplain of the Sacramento River, CA, USA. Hydrobiologia, 2004, 513 : 129-139.

[24] Leităo M, Morata SM, Rodriguez S et al. The effect of pertubations on phytoplankton assemblages in a deep reservoir (Vouglans, France). Hydrobiologia, 2003, 502: 73-83.

[25] 叶 麟, 徐耀阳, 蔡庆华. 香溪河库湾春季水华期间硝酸盐、磷酸盐的时空分布. 水生生物学报, 2006, 30 (1): 75-79.

[26] Redfield AC. The biological control of chemical factors in the environment. American Scientist, 1958, 46: 561-600.

[27] 郑丙辉, 曹承进, 张佳否等. 三峡水库支流大宁河水华特征研究. 环境科学, 2009, 30(11): 3218-3226.

[28] 黄 程, 钟成华, 邓春光等. 三峡水库蓄水初期大宁河回水区流速与藻类生长关系的初步研究. 农业环境科学学 报, 2006, 25(2): 453-457.

[29] 龙天渝, 刘春静. 三峡库区低流速河段流速对蓝、绿、硅藻垂直分布的影响. 科技信息, 2011, 13: 36-37. 